\title{
REACTIVATION POTENCY OF THE ACETYLCHOLINESTERASE REACTIVATOR OBIDOXIME IS LIMITED
}

\author{
Kamil Kuca ${ }^{\mathrm{a}, \mathrm{b} *}$, Kamil Musilek ${ }^{\mathrm{b}}$, Miroslav Pohankaa ${ }^{\mathrm{a}}$, Vlastimil Dohnal ${ }^{\mathrm{b}, \mathrm{c}}$, Jiri Patocka ${ }^{\mathrm{d}}$
}

a Center of Advanced Studies, Faculty of Military Health Sciences, University of Defence, Hradec Kralove, Czech Republic

${ }^{b}$ Department of Toxicology, Faculty of Military Health Sciences, University of Defence, Hradec Kralove

c Department of Chemistry, Department of Chemistry, Faculty of Sciences, J. E. Purkinje University, Usti nad Labem, Czech Republic

${ }^{d}$ Faculty of Health and Social Studies, University of South Bohemia, Ceské Budejovice, Czech Republic

e-mail:kucakam@pmfhk.cz

Received: July 10, 2009; Accepted: November 11, 2009

Keywords: Obidoxime/Acetylcholinesterase/Nerve agent/Pesticide/Antidote/Reactivator/Oxime

Background: Obidoxime is the only one reactivator of acetylcholinesterase (AChE) approved in Czech Republic for the treatment of nerve agent and pesticide poisonings for civilian sector. Due to the fact that misuse of nerve agents by terrorists or by an accidental poisoning by farmers is possible, re-evaluation of its universality is needed. It is also needed by the fact that clinical findings considering this oxime are controversial.

Aim: In this study, we wanted to summarize if obidoxime is a universal reactivator or if its reactivation potency in case of some organophosphorus inhibitors is limited.

Method: Using our in vitro method, rat brain $\mathrm{AChE}$ was inhibited by eleven organophosphorus $\mathrm{AChE}$ inhibitors and then reactivated by obidoxime.

Results and Conclusion: It was found that obidoxime could not be termed as universal antidote. Due to this, development of new promising candidates as replacement of obidoxime is recommended.

\section{INTRODUCTION}

Nerve agents (sarin, tabun, agent VX, etc.) and pesticides (paraoxon, chlorpyrifos, DDVP, etc.) pose relatively high threat to mammals. They are extremely toxic compounds, especially nerve agents, influencing nerve system. They inhibit enzyme acetylcholinesterase (AChE; EC 3.1.1.7) by the covalent binding to the hydroxyl group of serine in enzyme's active site. After the inhibition, enzyme is not able to split the neuromediator - acetylcholine $(\mathrm{ACh})$. ACh cumulates at the synaptic clefts, and due to this, subsequent cholinergic crisis occurs ${ }^{1-4}$.

At present time, only five $\mathrm{AChE}$ reactivators (pralidoxime, obidoxime, trimedoxime, methoxime and HI-6) together with atropine (cholinergic drug) and diazepam (anticonvulsive) are clinically used worldwide. In Czech Republic, three reactivators of them are available. However, only obidoxime can be used in civilian sector ${ }^{5-6}$.

Because of the fact, that we are living at the present time in the global war against terrorism, there is still a very high probability of the misuse of these compounds. Due to this, preparedness for the possible misuse of these agents is of high priority. As mentioned above, obidoxime is the only oxime introduced in the Czech civilian sector (Fig. 1). However in the current literature, the data discussing obidoxime antidotal potency are controversial ${ }^{7-11}$.

Owing to the above mentioned factors, summarization of the reactivation activities of obidoxime are shown in this article. For this purpose, eleven AChE inhibitors were selected. Tabun, sarin, cyclosarin, soman, VX agent, Russian VX were chosen as members of nerve agent group. Chlorpyrifos, paraoxon, methyl-chlorpyrifos, DDVP and DFP were chosen as members of the pesticide family. In vitro potentiometric method was used for the evaluation of obidoxime reactivation.

\section{MATERIAL AND METHODS}

Obidoxime (1,3-bis(4-hydroxyiminomethylpyridinium)2-oxapropane dichloride) was prepared at our department using the modified approach published earlier ${ }^{12}$. Its purity was determined prior its use by using TLC and HPLC ${ }^{13-14}$. Nerve agents were obtained from the Military Facility Brno (Czech Republic). Pesticides and all other chemicals used were obtained from Sigma-Aldrich (Czech Republic).

The whole in vitro method is described in the work of Musilek et al. ${ }^{15}$. Shortly: Lightly narcotized rats were killed (narcosis does not influence cholinesterase activity $)^{16}$. Their brains were removed and then homogenized with water to obtain $10 \%$ rat brain homogenate as the enzyme source. The brain homogenate $(0.5 \mathrm{ml})$ was mixed with isopropanol solution of $\mathrm{AChE}$ inhibitor and then incubated at $25^{\circ} \mathrm{C}$ for 30 minutes to achieve $95 \%$ inhibition of AChE. $2.5 \mathrm{ml}$ of solution of sodium chloride ( $3 \mathrm{M}$ ) were added to the mixture and filled to the volume $23 \mathrm{ml}$ with distilled water. Finally, $2 \mathrm{ml}$ of acetylcholine iodide solution $(0.02 \mathrm{M})$ were added. The enzyme activity was measured at $\mathrm{pH} 8.0$ and temperature $25^{\circ} \mathrm{C}$ on 
<smiles>[Y]OCN1C=C(C=N)C=C(C=NO)C=C1C=NO</smiles>

Fig. 1. Chemical structure of obidoxime.

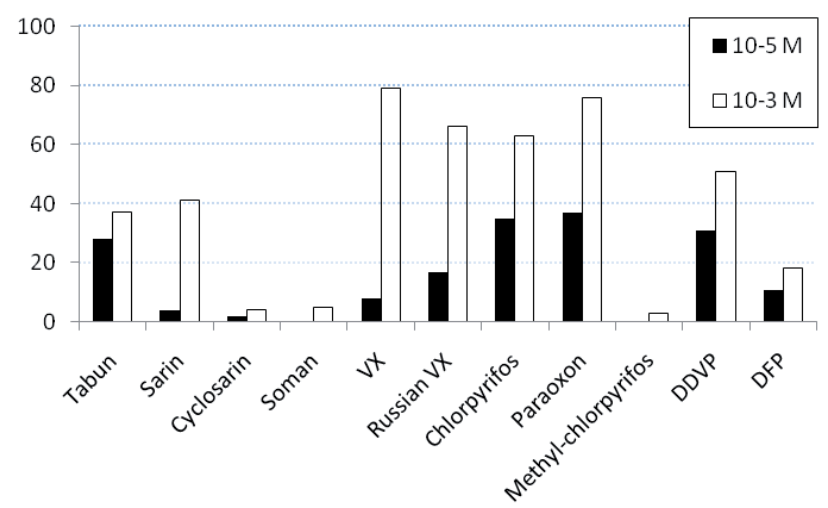

Fig. 2. Efficacy of oxime obidoxime in reactivation of different $\mathrm{AChE}$ inhibitors (\% reactivation); concentration of the obidoxime $10^{-3} \mathrm{M}$ and $10^{-5} \mathrm{M}$.

Table 1. Reactivation of nerve agents - and pesticideinhibited $\mathrm{AChE}$; concentration of the obidoxime $10^{-3} \mathrm{M}$ and $10^{-5} \mathrm{M}$.

\begin{tabular}{|l|c|c|}
\hline Nerve agent & $\begin{array}{c}\text { Reactivation [\%] } \\
\left(10^{-5} \mathrm{M}\right)\end{array}$ & $\begin{array}{c}\text { Reactivation [\%] } \\
\left(10^{-3} \mathrm{M}\right)\end{array}$ \\
\hline Tabun & 28 & 37 \\
\hline Sarin & 4 & 41 \\
\hline Cyclosarin & 2 & 4 \\
\hline Soman* & 0 & 5 \\
\hline VX & 8 & 79 \\
\hline Russian VX & 17 & 66 \\
\hline Chlorpyrifos & 35 & 63 \\
\hline Paraoxon & 37 & 76 \\
\hline $\begin{array}{l}\text { Methyl- } \\
\text { chlorpyrifos }\end{array}$ & 0 & 3 \\
\hline DDVP & 31 & 51 \\
\hline DFP & 11 & 18 \\
\hline
\end{tabular}

* In case of soman, only 15 min inhibition was used because of aging. autotitrator RTS 822 (Radiometer, Denmark). Activities of intact AChE (a0) and inhibited AChE (ai) were deducted from influence of consumption of $\mathrm{NaOH}$ solution $(0.01 \mathrm{M})$ on time. After the incubation with nerve agent or pesticide-inhibited $\mathrm{AChE}$ (30 minutes), the reactivator was added to the solution and the mixture and incubated for 10 minutes. Activity of reactivated AChE (ar) was calculated from the influence of consumption of $\mathrm{NaOH}$ solution on time.

The percentage of reactivation (\%) was calculated from measured data according to formula:

$$
x=\left(1-\frac{a_{0}-a_{r}}{a_{0}-a_{i}}\right) \cdot 100 \quad[\%]
$$

\section{RESULTS}

All the obtained results are summarized in Table 1 and Fig. 2. As resulted, obidoxime was able to reactivate $\mathrm{AChE}$ inhibited by all tested nerve agents and pesticides. As it is known, the sufficient reactivation potency causing survival of the intoxicated organism should be over $10 \%{ }^{17}$. From this point of view, cyclosarin-, soman - and methylchlorpyrifos-inhibited AChE was not sufficiently reactivated. At low for human relevant concentrations $\left(10^{-5} \mathrm{M}\right)$, obtained results are worse. At this concentration, only tabun, Russian VX, chorpyrifos, paraoxon, DDVP and DFP (limiting activity) reached sufficient reactivation activity.

\section{DISCUSSION}

Probability of organophosphorus pesticide poisoning is in Czech Republic relatively rare. Number of people intoxicated by pesticides is increased mostly in developing countries $^{18-20}$. On the contrary, possibility of nerve agent misuse or misuse of pesticides as low-toxic and accessible nerve agents is more probable in advanced countries by terrorists who do not like this kind consumer society.

Owing to this, preparedness for this threat is of great interest of scientists working in this area. Obidoxime is the only accessible reactivator available for the civilian sector in the Czech Republic. Its reactivation potency is according to the literature not so good to think that it is a universal antidote ${ }^{21-24}$. In our in vitro experiment, we confirmed this statement. If inhibitors such as cyclosarin, soman or methyl-chlorpyrifos would be misused, no antidote is available. Moreover, high doses of this oxime are needed to reactivate sufficiently - sarin and VX. However, high concentration of obidoxime could exert many side effects and in very high doses also death due to the cholinergic crisis ${ }^{25}$.

Intoxication of those nerve agents, which were not reactivated by obidoxime, could be then treated by using atropine only, anticonvulsives and other supportive treatment. Second possibility is to use military antidotes, especially oxime HI-6, which is considered to be broad- 
spectrum reactivator ${ }^{26-29}$. However, it is at present time not approved for civilian purposes.

Other possibility is to find quite new oxime which will be really universal antidote able to reactivate AChE inhibited by all nerve agents and pesticides. For this purpose, many laboratories throughout the world are working on this topic ${ }^{5,12,15,30-35}$.

Finally, combination of two oximes could solve this problem. This topic was already discussed in 1989 $\left(\right.$ ref. $\left.^{36,}{ }^{37}\right)$. Nowadays, several scientists re-open this approach. However, there will be probably problem with licensing of such antidotal mixture consisting of two compounds ${ }^{38}$.

\section{CONCLUSION}

In conclusion, $\mathrm{AChE}$ reactivator obidoxime is not a universal antidote applicable in all cases of organophosphorus AChE inhibitor poisonings. Due to this, it should be replaced by novel oximes such as HI-6 or novel candidates, which are just now only in laboratory testing phases.

\section{ACKNOWLEDGEMENT}

This work was supported by the project of the Ministry of Defence (Czech Republic) - No. FVZ0000501.

\section{REFERENCES}

1. Bajgar J. Organophosphates/nerve agent poisoning: mechanism of action, diagnosis, prophylaxis, and treatment. Adv Clin Chem 2004; 38: 151-216.

2. Zdarova Karasova J, Bajgar J, Novotny L, Kuca K. Is a high dose of Huperzine A really suitable for pretreatment against high doses of soman? J Appl Biomed 2009; 7: 93-99.

3. Marrs TC. Organophosphate poisoning. Pharmacol Ther 1993; 58: 51-66.

4. Kuca K, Kassa J. In vitro reactivation of acetylcholinesterase using of the oxime K027. Vet Hum Toxicol 2004; 46: 15-18.

5. Musilek K, Kuca K, Jun D, Dolezal M. Progress in synthesis of new acetylcholinesterase reactivators during the period 1990-2004. Curr Org Chem 2007; 11: 229-238.

6. Kovarik Z, Calic M, Vrdoljak AL, Radic B. Interaction of pyridinium oximes with acetylcholinesterase and their effect on organophosphate-poisoned mice. J Mol Neurosci 2006; 30: 113-114.

7. Petroianu GA, Arafat K, Nurulain SM, Kuca K, Kassa J. In vitro oxime reactivation of red blood cell acetylcholinesterase inhibitied by methyl-paraoxon. J Appl Toxicol 2007; 27: 168-175.

8. Petroianu GA, Hasan MY, Nurulain SM, Nagelkerke N, Kassa J, Kuca K. New K-oximes (K-27and K-48) in comparison with obidoxime (LuH-6), HI-6, trimedoxime (TMB-4) and pralidoxime (2-PAM): survival in rats exposed ip to the organophosphate paraoxon. Toxicol Mech Meth 2007; 17: 401-408.

9. Petroianu GA, Nurulain SM, Nagelkerke N, Shafiullah M, Kassa J, Kuca K. Five oximes (K-27, K-48, obidoxime, HI-6 and trimedoxime) in comparison with pralidoxime: survival in rats exposed to methyl-paraoxon. J Appl Toxicol 2007; 27: 453-457.

10. Pohanka M, Jun D, Kuca K. Photometric microplate assay for estimation of paraoxon inhibited acetylcholinesterase reactivation efficacy. J Enzyme Inhib Med Chem 2008; 23: 781-784.
11. El-Naggar AR, Abdalla MS, El-Sebaey AS, Badawy SM. Clinical findings and cholinesterase levels in children of organophosphates and carbamates poisoning. Eur J Pediatr 2009; 168: 951-956.

12. Musilek K, Holas O, Kuca K, Jun D, Dohnal V, Dolezal M. Synthesis of the novel series of asymmetrical bispyridinium compounds bearing xylene linker and evaluation of their reactivation activity against tabun and paraoxon-inhibited acetylcholinesterase. J Enzyme Inhib Med Chem 2007; 22: 425-432.

13. Jun D, Stodulka P, Kuca K, Koleckar V, Dolezal B, Simon P, Veverka M. HPLC analysis of HI-6 dichloride and dimethanesulfonate - antidotes against nerve agents and organophosphorus pesticides. Anal Lett 2007; 40: 2783-2787.

14. Jun D, Stodulka P, Kuca K, Koleckar V, Dolezal B, Simon P,Veverka M. TLC analysis of intermediates arising during the preparation of oxime HI-6 dimethanesulfonate. J Chrom Sci 2008; 46: 316-319.

15. Musilek K, Holas O, Kuca K, Jun D, Dohnal V, Opletalova V, Dolezal M. Synthesis of Monooxime-Monocarbamoyl Bispyridinium Compounds bearing (E)-but-2-ene Linker and Evaluation of their Reactivation Activity against Tabun - and Paraoxon-Inhibited Acetylcholinesterase. J Enzyme Inhib Med Chem 2008; 23: 70-76.

16. Novotny L, Karasova J, Kuca K, Bajgar J, Misik J. Influence of different wals of euthanasisa on the aktivity of cholinesterases in the rat. J Appl Biomed 2009; 7: 115-118.

17. Bajgar J, Kuca K, Jun D, Bartosova L, Fusek J. Cholinesterase reactivators: the fate and effects in the organism poisoned with organophosphates/nerve agents. Curr Drug Metab 2007; 8: 803-809.

18. Li Y, Sun C, Qiu Z, Ma S, Yu X, Wang Z, Eddleston M. Clinical toxicology in China: current situation and future development. Clin Toxicol (Phila) 2009; 47: 263-269.

19. Wickramasinghe K, Steele P, Dawson A, Dharmaratne D, Gunawardena A, Senarathna L, de Siva D, Wijayaweera K, Eddleston M, Konradsen F. Cost to government health-care services of treating acute self-poisonings in a rural district in Sri Lanka. Bull World Health Organ 2009; 87: 180-185.

20. Eddleston M, Buckley NA, Eyer P, Dawson AH: Management of acute organophosphorus pesticide poisoning. Lancet 2008; 371 : 597-607.

21. Lorke DE, Hasan MY, Arafat K, Kuca K, Musilek K, Schmitt A, Petroianu GA. In vitro oxime protection of human red blood cell acetylcholinesterase inhibited by diisopropyl-fluorophosphate. J Appl Toxicol 2008; 28: 422-429.

22. Lorke DE, Hasan MY, Nurulain SM, Sheen R, Kuca K, Petroianu GA. Entry of two new asymmetric bispyridinium oximes (K-27 and K-48) into the brain: comparison with obidoxime. J Applied Toxicol 2007; 27: 482-490.

23. Lorke DE, Nurulain SM, Hasan MY, Kuca K, Musilek K, Petroianu GA. Eight new bispyridinium oximes in comparison with the conventional oximes pralidoxime and obidoxime: In vivo efficacy to protect from diisopropylfluorophosphate (DFP) toxicity. J Appl Toxicol 2008; 28: 920-928.

24. Gholivand K, Mojahed F, Salehi M, Naderi-Manesh H, Khajeh K. Synthesis, characterization and inhibitory potency of two oxono and thiono analogues of phosphoramidate compounds on acetylcholinesterase. J Enzyme Inhib Med Chem 2006; 21: 521-525.

25. Bartosova L, Kuca K, Kunesova G, Jun D. The acute toxicity of acetylcholinesterase reactivators in mice in relation to their structure. Neurotox Res 2006; 9: 291-296.

26. Kuca K, Kassa J. Oximes-induced reactivation of rat brain acetylcholinesterase inhibited by VX agent. Hum Exp Toxicol. 2004; 23 : 167-171.

27. Kassa J, Jun D, Kuca K. A comparison of reactivating efficacy of newly developed oximes (K074, K075) and currently available oximes (obidoxime, HI-6) in cyclosarin and tabun-poisoned rats. J Enzyme Inhib Med Chem 2007; 22: 297-300.

28. Kassa J, Karasova J, Bajgar J, Kuca K, Musilek K. A comparison of the therapeutic and reactivating efficacy of newly developed bispyridinium compounds (K206, K269) with currently available oximes against tabun in rats and mice. J Enzyme Inhib Med Chem 2008; 23: 776-780.

29. Lundy PM, Raveh L, Amitai G. Development of the bisquaternary oxime HI-6 toward clinical use in the treatment of organophosphate nerve agent poisoning. Toxicol Rev 2006; 25: 231-43. 
30. Kuca K, Jun D, Bajgar J. Structural factors influencing potency of currently used acetylcholinesterase reactivators for treatment of cyclosarin intoxications. Curr Pharm Des 2007; 13: 3445-3452.

31. Kuca K, Racakova V, Jun D. Relationship between structure of chlorpyrifos-inhibited acetylcholinesterase reactivators and their biological activity. Chem Pap 2007; 61: 256-261.

32. Musilek K, Jun D, Cabal J, Kassa J, Gunn-Moore F, Kuca K Design of a potent reactivator of tabun-inhibited acetylcholinesterase - Synthesis and evaluation of (E)-1-(4-carbamoylpyridinium)-4(4-hydroxyiminomethylpyridinium)-but-2-ene dibromide (K203). J Med Chem 2007; 50: 5514-5518.

33. Musilek K, Kuca K, Jun D, Dolezal M. In vitro reactivation potency of bispyridinium ( $E$ )-but-2-ene linked acetylcholinesterase reactivators against tabun-inhibited acetylcholinesterase. J Appl Biomed 2007; 5: 25-30.
34. Kim TH, Kuca K, Jun D, Jung YS. Design and synthesis of new bis-pyridinium oximes as cyclosarin-inhibited acetylcholinesterase reactivators. Bioorg Med Chem Lett 2005; 15: 2914-2917.

35. Kim TH, Oh KA, Park NJ, Lim YJ, Yum EK, Jung YS. Reactivation study of pyridinium oximes for acetylcholinesterases inhibited by paraoxon or DFP. J Appl Biomed 2006; 4: 67-72.

36. Kovacevic V, Maksimovic M, Deljac V, Binenfeld Z. The efficacy of 1,1'-(1,4-buten)-bis-(4-hydroxyiminomethyl-pyridinium) dibromide in the treatment of organophosphate poisoning. Acta Pharm 1989; 39: 167-170.

37. Kovacevic V, Maksimovic M, Pantelic D, Vojvodic V, Binenfeld Z. Protective and reactivating effects of HI-6 PAM-2 mixture in rats with nerve chemical warfare agents (nerve CWA). Acta Pharm 1989; 39: 161-165.

38. Worek F, Aurbek N, Thiermann H. Reactivation of organophosphate-inhibited human AChE by combinations of obidoxime and HI 6 in vitro. J Appl Toxicol 2007; 27: 582-588. 